32 Tropelías. Revista de Teoría de la Literatura y Literatura Comparada, número extraordinario 1 (2017) Natalia Álvarez Méndez

\title{
LÍNEAS ÉTICAS Y ESTÉTICAS EN LA NARRATIVA GUINEOECUATORIANA EN LENGUA ESPAÑOLA
}

\author{
Natalia ÁLVAREZ MÉNDEZ \\ Universidad de León \\ natalia.alvarez@unileon.es
}

\begin{abstract}
A José Enrique Martínez Fernández, como humilde contribución al homenaje con motivo de su jubilación, con el agradecimiento eterno por su generoso magisterio y su amistad, y por tantos momentos académicos compartidos y disfrutados que han fortalecido mi vocación y se atesoran en la memoria.
\end{abstract}

$\mathrm{E}$

n el ámbito negroafricano la creación literaria, cada vez más dinámica, es un fiel reflejo del sufrimiento histórico potenciado por el proceso de colonización de sus territorios, así como por el neocolonialismo y la actual globalización. En el caso específico de la escritura hispanonegroafricana de Guinea Ecuatorial se puede advertir cómo los diferentes períodos vividos - colonial, neonacional o de independencia, y neocolonial-, han afectado al rumbo de su evolución al condicionar la identidad existencial y cultural del pueblo ecuatoguineano y, por ende, la de sus intelectuales y escritores.

Los procesos históricos padecidos por la sociedad guineoecuatoriana dan lugar a confluencias culturales pero, también y de modo inevitable, a contradicciones vitales y culturales que quedan reflejadas en una escritura comprometida. De este modo, alejándose del concepto occidental del arte por el arte, destaca la función social de su creación literaria, siendo los escritores baluartes de un gran compromiso ético y una responsabilidad intelectual que les conduce ineludiblemente a ser portavoces de la historia colectiva y de la reafirmación de la identidad africana ${ }^{1}$, en muchos casos desde la transterritorialidad o transcontinentalidad causada por el exilio o la migración. Por tales motivos la ficción narrativa está unida a la memoria colectiva y a la historia de su pueblo ${ }^{2}$, e incide tanto en la

\footnotetext{
${ }^{1}$ Las siguientes palabras de Ndongo-Bidyogo ilustran dicho compromiso ético: «El escritor africano, sobre todo, es un marginado entre los marginados, es la voz de los sin voz, que en nuestros países constituyen la mayoría de la población. El escritor es un hombre o una mujer que han escogido deliberadamente un oficio ingrato cuya única satisfacción está en la tranquilidad de la conciencia, en saberse algo así como la conciencia moral de la sociedad. En la medida en que un escritor profundiza en ese campo, es cuando llega a producir una obra madura, permanente, universal, que llegue a interesar a gran parte del mundo, hasta alcanzar eso que se llama consagración» (En N'gom Faye, 1996: 89-90).

${ }^{2}$ En este hecho incide, entre otros estudios, el volumen monográfico compilado por N'gom (2004).
} 
autonomía y liberación del sujeto como en las posibilidades futuras del país a todos los niveles mediante una literatura consciente de la necesidad de retomar las riendas de su propio destino.

Así pues, esta literatura que reflexiona sobre África y el africano consolidando una conciencia nacional caracterizada por los componentes tribales, a pesar de ser susceptible, sobre todo en sus más recientes manifestaciones, de ser analizada desde una reformulación de los parámetros teóricos y críticos empleados hasta el momento ${ }^{3}$, a su vez, no puede dejar de ser abordada atendiendo a la citada perspectiva histórica y referencial a la que ha de sumarse inevitablemente la revisión de su estética textual. De ahí se deriva el interés de estas páginas en reseñar las líneas éticas y estéticas de la prosa de ficción guineoecuatoriana.

Entre los integrantes de la nómina literaria narrativa del período de independencia y dictadura nguemista, conocido como 'los años del silencio’, destacan Juan Balboa Boneke (Rebola, 1938), María Nsué Angüe (Ebebeyín, 1945), Francisco Zamora Loboch (Malabo, 1948), Donato Ndongo-Bidyogo (Niefang, 1950), entre otros. Dichos escritores, con una narrativa en gran medida costumbrista, histórica y con contenidos etnográficos, abordarán temas marcados por la difícil experiencia de la etapa colonial y del período de independencia. En esos 'años del silencio', a consecuencia del régimen impuesto por Macías, es preciso esperar hasta finales de la década de los 70 para que se edite la obra titulada Nueva narrativa guineana, compuesta por cuatro relatos que abarcan motivos como la colonización, la trata de esclavos, la separación forzosa de la tierra natal y las precarias condiciones de vida sufridas por los africanos que han inmigrado a países europeos. A partir de ese momento se potencia el cultivo de diferentes géneros y se amplía la temática literaria, desarrollándose con fuerza la resistencia cultural que logra recrear desde la posición periférica del exilio la traumática situación vivida en Guinea Ecuatorial ${ }^{4}$. La literatura postcolonial y neonacional guineoecuatoriana ofrece, pues, muestras de una creación caracterizada por la resistencia al discurso colonial y neocolonial y, por lo tanto, por una política específica de representación del mundo y del modo de percibirse. Esta se concreta en el intento de constitución de una literatura nacional mediante dos mecanismos esenciales: el rechazo de la ideología colonizadora, tal como postulaba Fanon (1961), y el empleo, analizado por Bhabha $(1990,1994)$, de los propios instrumentos estéticos del dominador para desplazar la autoridad impuesta.

En el contexto y período mencionado, sobresalen ejes de desarrollo como, entre otros, la memoria y el conflicto entre tradición y modernidad con el inevitable reencuentro con la sabiduría ancestral de las diversas etnias y tribus; la función social de la creación literaria; y el exilio de intelectuales, con la imposibilidad de regreso y el desarraigo en la diáspora.

En un primer momento, en relación con el conflicto entre tradición y modernidad, se rechaza la imposición de esta última por parte del colonizador. La tradición vernácula se muestra como la solución para la definición identitaria y como alternativa de sustitución de la cultura colonial en el

\footnotetext{
${ }^{3}$ Como se puede apreciar, por ejemplo, en algunas de las propuestas planteadas en el volumen 28 de Afro-Hispanic Review dedicado a la creación de Guinea Ecuatorial (Sampedro Vizcaya y Fra-Molinero, 2009).

${ }^{4}$ En esa línea destacan los esfuerzos de la Generación Perdida, desde cuya perspectiva Juan Manuel Davies revisa la historia de Guinea Ecuatorial en su ensayo novelado Siete días en Bioko (2007).
} 
camino hacia la construcción de la expresión de una identidad cultural propia. Así, por ejemplo, en Ekomo (1985), novela de María Nsué Angüe, se refleja el contraste entre el poblado y la ciudad, la medicina nativa y los hospitales occidentales, así como las creencias tradicionales y las extranjeras. En la novela de Juan Balboa Boneke titulada El reencuentro. El retorno del exiliado (1985), se recrea la nostalgia por el mundo milenario africano tras la decepcionante vivencia europea, insistiendo en recuperar la relación armónica con la naturaleza y con el sentido comunitario africano que se integraban en la cultura autóctona. En este sentido, sobresale la relación de las voces de los escritores con la notación geográfica. Es decir, el modo en que conciben su origen, vinculándolo al entorno espacial y en ocasiones tribal al que pertenecen, y cómo esto afecta a sus creaciones literarias. Asimismo, estos escritores participan en cierto grado con su literatura de resistencia de lo que Said denominó como 'reinscripción', una forma de contraescritura que trata de recuperar, a través de la imaginación literaria, la geografía arrebatada por la acción colonial. Finalmente, en etapas más avanzadas, dicho conflicto entre tradición y modernidad se resuelve mediante la aceptación de una síntesis armoniosa y positiva que permita avanzar a la sociedad ${ }^{5}$.

Existen otros motivos — como la búsqueda desesperada de una identidad hispanonegroafricana del sujeto postcolonial híbrido, así como de bienestar y de libertad; la miseria generalizada; la opresión del negro por el negro; la corrupción y crueldad de los gobernantes; la condición de la mujer guineana en una sociedad patriarcal; etc.- - que se abordan desde la función social de la creación literaria que parece mantener la labor de transmisión cultural que en tiempos remotos llevaban a cabo los griots. De tal manera, logran contar la historia colectiva que se había visto truncada con la llegada del colonizador y a causa de la alienación impuesta al colonizado. «De ahí que esta función social enlace en muchos casos con una determinada posición política que se traduce en el deseo de rescatar el pasado que reconstruya la africanidad de su pueblo y que eduque a sus miembros al respecto de su propia identidad» (Álvarez Méndez, 2010: 127).

Dicha función social se ejerce inevitablemente desde el exilio conformando la identidad de la nueva literatura guineoecuatoriana desde la insistencia en la necesidad de mantener un contacto cotidiano con la temática socio-cultural tribal, guineana y africana. Entre otras obras, un ejemplo que ilustra la vivencia provocada por la diáspora es El reencuentro. El retorno del exiliado (1985), de Juan Balboa Boneke. En esta novela se presenta el relato del viaje del protagonista a Guinea Ecuatorial tras diez años de exilio en Palma de Mallorca. Por otra parte, Ndongo-Bidyogo, autor profundamente implicado en la búsqueda de las señas de identidad de los guineanos, escribe en un contexto totalmente postcolonial, subversivo y reivindicativo de la africanidad, Las tinieblas de tu memoria negra (1987), novela que, localizada en los últimos años de la etapa colonial, surge del interés del autor por remendar el desplazamiento sufrido por la cosmogonía tradicional a causa de la colonización reflejando, a su

\footnotetext{
5 Tal como expone Ndongo-Bidyogo: «Tradición literaria para que nos sintamos seguros y fortalecidos en nuestra tarea cotidiana, sabiendo que no somos hijos del aire, que somos depositarios de un legado milenario que nos otorga una personalidad, una esencia, una cultura propia. Y modernidad, necesaria para no quedar anquilosados frente a la evolución de un mundo especialmente cambiante, para ser hijos de nuestro siglo sin complejos ni frustraciones» (Ndongo-Bidyogo y N'gom, 2000: 55).
} 
vez, la relevancia de la memoria colectiva en el camino hacia la recuperación de la propia identidad; y que se complementa con Los poderes de la tempestad (1997), que incide directamente en el duro período de independencia y que «es uno de los ejemplos más significativos del peregrinaje sufrido por los guineoecuatorianos en el exilio y de su deseo de retorno a la tierra de los antepasados. Esa añoranza es la que pone en peligro de muerte al protagonista y a su familia» (Álvarez Méndez, 2010: 170).

El género narrativo, caracterizado por los ejes de desarrollo mencionados hasta el momento, tiene en el conjunto de la creación guineoecuatoriana una gran relevancia, destacando su cultivo en relación con la transmisión de temas sociales e ideológicos. En esa línea,

[...] se advierte la evolución desde la temática tradicional y local hacia el cultivo de motivos vinculados al neonacionalismo — el exilio, la dictadura, la reivindicación del pasado ancestral, etc., pero nunca un anticolonialismo beligerante-; y, posteriormente, a los relacionados con el neocolonialismo, — con la denuncia centrada en la reivindicación de la libertad y de una vida digna para todos los guineoecuatorianos-. En todas esas fases la temática diversa siempre unificada por el rasgo de costumbrismo propio de esta escritura.

En el período postcolonial se encamina la literatura hacia el desarrollo de moldes genéricos y temas y tipos literarios cada vez más relacionados con un intento de expresión del nacionalismo identitario. Surgen, pues, usos políticos de la literatura vinculados a la construcción de la nueva nación y a la recreación de un pasado idílico que sirva para mirar el presente y el futuro de manera personal y no alienada. [...] El fenómeno de la descolonización da lugar a unos moldes genéricos recurrentes, a través de los cuales se manifiesta fácilmente la voz de los subalternos y su resistencia cultural ante el imperio. Entre ellos, relacionados con estrategias de supervivencia de la propia identidad, resaltan apropiaciones del género novelístico por parte de los colonizados que hacen evolucionar su literatura desde la oralidad al memorialismo. La inclusión de la literatura oral es concebida por los escritores postcoloniales como un vehículo de conexión con la verdadera tradición que posibilita el alcance de una nacionalidad identitaria. Se cultiva, así, la confesión, el relato testimonial o la historia de una vida, es decir, autobiografías simbólicas y colectivas (Álvarez Méndez, 2010: 179-180).

Si un elemento más caracteriza esta etapa es el peso de la cultura oral precolonial en la obras de estos autores, que tratan de integrar la oralidad propia de la tradición africana a la escritura importada desde Occidente, pues en su literatura se unen «las exigencias formales, estilísticas y técnicas de la tradición literaria y las reglas más pragmáticas y flexibles de la tradición oral» (Uribe, 2004: 96). De tal modo, por ejemplo, María Nsué Angüe escribe su novela Ekomo en primera persona, con la repetición de frases y recursos tipográficos que nos acercan al lenguaje coloquial y oral. También Ndongo-Bidgyogo, creador de la autobiografía de la sociedad guineana actual, emplea recursos tipográficos próximos a la comunicación oral, así como «frases largas, la conjunción “y”, la repetición de palabras o frases, el monólogo interior, el paréntesis para comentarios y el discurso directo intercalado en la narración» (Uribe, 2004: 98). A su vez, reconoce haber utilizado técnicas narrativas procedentes de su grupo étnico de los fang: «cuando en mi grupo se cuenta algo, el narrador procura incorporar poco a poco a sus personajes las características de personas que conoce, lo cual no significa que estos personajes sean exactamente dichas personas» (Zielina, 2000: 19).

En los últimos años, si hay una obra de esta generación que se constituye en una fiel síntesis de todos los motivos citados hasta el momento es El metro (2007), de Donato Ndongo-Bidyogo, uno de los escritores que conjuga estética y compromiso, tal como se constata en el artículo más actualizado 
de Álvarez Méndez (2015) ${ }^{6}$. En la novela, narrada en tercera persona, el camerunés Lambert Obama Ondo, del clan de los yendjok de la etnia fang, nos traslada mediante un complejo viaje desde la aldea y la selva hasta la ciudad y, después, a Occidente y al metro ${ }^{7}$, experimentando en todos esos ámbitos la insolidaridad y el egoísmo alejados de la tradicional hospitalidad africana, incluso en las propias ciudades africanas en las que no existe cohesión social entre las diversas etnias. Se plantean en la novela, entre otros motivos, el enfrentamiento entre Europa y África; la visión crítica del colonialismo y del neocolonialismo; la lucha y el posterior sincretismo de la cultura occidental y la negroafricana; la problemática de la identidad en un contexto híbrido; el intento de resistencia de la tradición africana frente a la modernidad ineludible; así como las contradicciones experimentadas por el africano en tierras lejanas a la materna; y la subalternidad de la mujer africana revelada en el discurso de los personajes femeninos. Todo ello reflejado a través de estrategias narrativas como la estructura circular de la novela, la pluralidad de voces, recurrentes preguntas retóricas y destacados monólogos interiores.

Por otra parte, a partir de la década de los 90 del siglo XX, sobresale la vigencia de la generación de la segunda República, que en su mayoría han realizado su formación fuera de Guinea Ecuatorial pero que viven la realidad del obiangnguemismo, a pesar de no haber sufrido en todos los casos la colonización ni la dictadura de Macías, y que manifiestan en sus obras una problemática concretada en la corriente conocida como 'nuevo costumbrismo nacional' o 'nueva narrativa nacional'. En este segundo grupo resaltan nombres como José Siale Djangany (Malabo, 1961), Juan Tomás Ávila Laurel (Malabo, 1966), Maximiliano Nkogo Esono (Evinayong, 1972), César A. Mba Abogo (Bata, 1979), entre otros.

A medio camino, pues es definido por algunos como el autor más joven de la generación anterior y por otros como uno de los destacados nuevos nombres de la última narrativa guineoecuatoriana, sobresale Joaquín Mbomio Bacheng (Niefang, 1956), escritor que sí vive la anterior dictadura. Por ello plantea, con elementos autobiográficos, en sus dos novelas tituladas El Párroco de Niefang (1996) y Huellas Bajo Tierra (1998), la crudeza del período dictatorial de Macías Nguema. En ambas obras muestra un concepto de identidad condicionado por la hibridez cultural europea y africana, optando por el sincretismo religioso que resuelva el conflicto entre tradición y modernidad, y denunciando el neocolonialismo.

Pero, centrando la atención en los escritores de la segunda República, se constata que se trata de una generación cuyas líneas estéticas siguen íntimamente articuladas en el compromiso social y político de sus escritores. No obstante, sustituyen algunos de los anteriores temas próximos a la

\footnotetext{
${ }^{6}$ Así se perfila también en el estudio de Otabela y Onomo Abena (2008).

7 «La novela presenta, al menos, un doble viaje iniciático: el que se nos permite realizar a los lectores no africanos para que conozcamos las idiosincrasia, instituciones, tradiciones y costumbres del pueblo bantú (tribu, clan, etnia, familia, dote, rapto, poligamia, brujería, medicina tradicional, ritos de iniciación, roles del hombre y la mujer, pertenencia de los hijos a la familia del padre o de la madre, entierros, rito del viudo después de la muerte de la esposa, reparto de los bienes de la esposa y culto a los muertos, hospitalidad familiar, etc.) y un segundo viaje, lento, duro y material, que emprenderá el emigrante Lambert Obama Ondo (a pie, en barco como polizonte, en autobús, en avión, en furgoneta, en patera, de nuevo en avión, en coche y en metro) atravesando países de África subsahariana y el Magreb hasta llegar a la tierra de los blancos, a Europa» (Nistal Rosique, 2008: 111).
} 
tradición oral por otros más universales y vinculados a la realidad inmediata y cotidiana. Todos ellos describen en sus obras las vicisitudes sufridas por el guineoecuatoriano de a pie, aunque confluyen inevitablemente con los escritores de la generación perdida en el deseo de superación de las experiencias negativas padecidas históricamente por su pueblo y en la problemática de la identidad mestiza, múltiple y sincrética. Por ello, abordarán la realidad de la nueva «independencia» y los problemas actuales del continente, como la dictadura, la emigración, el racismo, la miseria, el desencanto por las promesas rotas, la ausencia de verdadera libertad, la corrupción, el neocolonialismo, la armonía con la tradición secular en el camino hacia el progreso y la modernidad, etc.

Se ha establecido que la conocida como Generación perdida manifiesta unas preocupaciones muy concretas en las que prima la realidad sobre la ficción, con «una literatura a la vez costumbrista, histórica y social» (Otabela Mewolo y Onomo-Abena, 2004: 29). Frente a ese rasgo costumbrista o quizá, más bien, cercano al folclore — que da a conocer la cultura y la tradición de las diferentes etnias oponiendo lo africano a lo occidental—, y frente a los temas relacionados con la historia del país, es la tercera vertiente, la social, la que más une a la Generación perdida con los escritores de la nueva narrativa guineana. De tal modo, aunque se siguen perfilando motivos folclóricos e históricos, la narrativa última se abre a temas universales, y refleja la realidad inmediata y las vivencias cotidianas caracterizándose por una marcada tendencia social.

Tras haber afirmado que prosiguen manteniendo una literatura comprometida con la realidad del mundo africano, es preciso advertir que en la vertiente estética es donde sobresalen los mayores cambios respecto a los escritores precedentes. En líneas generales, se puede aseverar que desarrollan una narrativa marcada por el empleo de un lenguaje cuidado que incluye giros idiomáticos, localismos y la recreación del habla popular. A su vez, conjugan en su escritura elementos propios de la tradición oral con elementos estéticos contemporáneos que conectan con la modernidad occidental. Entre los primeros figuran, por ejemplo, la forma oral otorgada a la palabra escrita, la repetición de frases o fórmulas, la inclusión de pequeños relatos en el seno de narraciones extensas, las apelaciones a un posible espectador-oyente, etc. Entre los segundos, de forma sucinta, se puede citar la utilización de estructuras de bildungsroman, la intertextualidad, la metaficción, la autoficción, el denominado como realismo mágico africano, junto a otras estrategias narrativas como el sueño, la imaginación, la ironía o lo grotesco. En suma, dan muestras de la hibridez cultural guineoecuatoriana en unas creaciones literarias que se orientan y se abren hacia otras tradiciones culturales sin perder en ningún momento su propia esencia.

Por poner algún ejemplo concreto de ambas vertientes, éticas y estéticas, y empezando nuevamente por la primera de ellas, se puede citar inicialmente a uno de los autores más destacados de la nueva narrativa nacional o neo-independentista, José Siale Djangany, que ofrece una visión de la realidad colonial y postcolonial del país, abordando motivos como el de la construcción de la identidad y la corrupción, entre otros. Si en los relatos de La revuelta de los disfraces (2003) denuncia tanto la corrupción de los poderosos como la alienación cultural del negro que debería rechazar los modelos occidentales para recuperar la africanidad, un semejante compromiso ético se refleja en sus novelas. 
En Cenizas de Kalabó y Termes (2000) incide en la compleja situación de decadencia que se desarrolla desde la transición del colonialismo a la afirmación de una independencia limitada por los abusos de los nuevos gobernantes y por las consecuencias de la dictadura ${ }^{8}$. A su vez, en Autorretrato con un infiel (2007) ofrece una visión del mundo poscolonial al atender a la historia nacional con el fin de configurar una caricatura de la corrupción política y de las luchas internas generadas por la colonización y la descolonización. En su discurso pone de manifiesto la represión política y la tiranía que reina sobre el territorio citado. Se denuncia que gran parte de la responsabilidad del odio y de la desconfianza que se ciernen sobre esa tierra es culpa de la metrópoli que propaga los prejuicios sobre los beséberes, negando su aptitud humana para creer en el Dios católico y entendiendo que no tienen ninguna otra identidad cultural por la que luchar que la impuesta por la metrópoli. Todo ello gracias a la actitud de extensión de un nuevo colonialismo apoyada por el exterior y sumada al nombramiento de un presidente vitalicio que potencia el totalitarismo y la represión.

Juan Tomás Ávila Laurel, que ejerce la actividad literaria en su propio país sin experimentar el exilio, es un escritor muy comprometido con su tierra, que despliega una mirada crítica sobre la realidad social, política y económica del país, denunciando las desigualdades, la marginación, la pobreza, etc., e incidiendo, para ello, tanto en la época colonial esclavista como en la neonacional de la dictadura con la opresión prolongada del guineoecuatoriano.

Si se centra la atención en las publicaciones de los últimos años, la novela titulada Avión de ricos, ladrón de cerdos (2008), evoluciona entrelazando de modo hábil las vivencias en Malabo del protagonista, guineano de la etnia fang, y toda su historia familiar y de la gente que con él se cruza en algún momento de su existencia, desarrollando historias y personajes secundarios a través de un destacado ritmo narrativo que nos conduce desde la actualidad a tiempos anteriores. En la novela se ponen de relieve desde una perspectiva comprometida, entre otros aspectos: la miseria sufrida en Bata; la crítica a un médico de una ONG que abusa de chicos africanos mientras ejerce como cooperante dando a entender un desinterés inexistente; curas que no cumplen con el voto de castidad que predican; el sacerdocio como medio para salir de la pobreza y escalar posiciones en la sociedad; la peligrosa situación política que se experimenta y que da lugar a que cualquiera pueda ser detenido, torturado y condenado a pesar de no ser culpable del hecho del que se le acusa; la historia de familiares como Mba Ndong, con vocación de trovador y denominado como Yambambé Yambambó, que luchó por mantener la independencia de Guinea a partir de 1979 en un período de deterioro político y social sin recibir la recompensa merecida por luchar contra las fuerzas antimacistas por el hecho de pertenecer a la otra rama del grupo de poder de la provincia, un clan no afín al de Macías; así como también críticas a la pérdida de la tradición, a la perpetuación de la historia esclavista de la gente de la tierra tras la

\footnotetext{
${ }^{8}$ De manera más concreta, como ha afirmado Nistal Rosique: «La novela toca directa o indirectamente algunos temas de la sociedad en general: la violencia doméstica $(58,143,148)$, la homosexualidad (65, 85-86), el aborto (57); y de la sociedad africana en particular: poligamia y promiscuidad (página 52, 58, 67, 177), la pobre consideración de la mujer (141, 231), las actitudes dictatoriales y los abusos militares (páginas 109, 173-174, 192, 198, 215), la brujería y la superstición (91, $115,182)$, los juicios sin garantías con ejecución injusta y cese de chivo expiatorio una vez que el asunto salta a la prensa internacional (164-179)» (2008: 124).
} 
independencia, con el nepotismo y el tráfico de influencias, y al hambre que sufren los negros de países dominados por oligarquías sin que nadie haga nada por evitarlo.

Arde el monte de noche (2009), la última novela publicada por Juan Tomás Ávila Laurel, le convierte en el «cronista trasterrado de Annobón» ${ }^{9}$. La narración se centra en la evocación de la infancia y en las desoladoras vivencias de los habitantes de una isla del mar de Atlante sometida al aislamiento por parte de la jerarquía política hasta el punto de que sufren en auténtica soledad abundantes estrecheces — carestía, cólera, etc.—, mientras la única ayuda que les llega del exterior es la de ciertos barcos de naciones extranjeras, de blancos que explotan la riqueza de sus aguas y que de modo muy puntual les ceden algún bien material. También se recogen en la novela ciertas críticas a determinadas situaciones, entre ellas, la actuación de los religiosos de la Misión en la isla y la opresión del negro por el negro.

Otro de los escritores de esta generación, Maximiliano Nkogo Esono ofrece en Adjá-Adjá y otros relatos, un testimonio de la realidad de la sociedad guineana actual que ha de enfrentarse a las miserias propias de la vida diaria en un país desintegrado y desestructurado política y socialmente, sin referentes morales sólidos. De ahí que realice constantes críticas al desolador período de independencia de la nueva nación guineoecuatoriana que abarca desde el mandato de Nguema hasta la prolongación del antidemocrático sistema del obiangnguemismo, caracterizados ambos por la corrupción que empuja al individuo a actuar contra la comunidad con el fin de poder sobrevivir alcanzando así necesidades básicas. A su vez, en Nambula (2007) presenta, desde la perspectiva de un familiar de un político relevante, el retrato de una ciudad de un pequeño país africano subsahariano en transición donde destaca la corrupción que asola a las antiguas colonias africanas mediante la violencia, la represión, el nepotismo, la deficiente sanidad y la escasez de alimentos en buen estado. En su última narración, Ecos de Malabo (2009), muestra a través de diversos relatos un completo retrato de los grandes contrastes que acoge en su seno la realidad de la vida en Malabo, la capital del país.

Por su parte, César A. Mba Abogo es un escritor comprometido con la difusión de la realidad actual africana que regresa a su país natal en el año 2006. Con su libro de 2007, titulado El porteador de Marlow. Canción negra sin color, se perfila como un destacado creador de la nueva narrativa guineana, manteniendo la perspectiva ética y comprometida de la escritura africana. Manifiesta en dicha obra la problemática de la concepción de la identidad personal y el conflicto cultural y psicológico experimentado a consecuencia de la hibridación entre África y Europa, conjugando las preocupaciones específicas del contexto vital, histórico y cultural africano con las universales de cualquier individuo. En un viaje literario de África a Europa y el consiguiente regreso al lugar originario, el autor nos ofrece un retrato profundo de la desgarrada situación africana y de las

\footnotetext{
${ }^{9}$ Así lo afirma, en el prólogo a la novela, José Manuel Pedrosa: «De aquellas selvas y de aquellas playas de Annobón nace también, por supuesto, la literatura de Juan Tomás, que es una literatura que reúne los ingredientes típicos del relato de frontera: un poco de épica, algo de tragedia, la sinceridad descriptiva y de un memorialismo que tiene mucho de biográfico y no poco de etnográfico. Y, planeando por encima de todo, la conciencia (profundísimamente arraigada en el ideario del autor) de cumplir la función de habitante, testigo y cronista de un margen (geográfico, linguiístico, cultural) desde el que se contempla muy lejano el centro, y muy cercano el abismal azul» (2009: 8).
} 
implicaciones europeas en la misma. Da paso en sus textos a la descripción de la corrupción, la violencia en todos sus grados, la pobreza, la emigración, el atraso, la discriminación, el racismo, la incomprensión, y el amor.

En cuanto a la estética, además del cultivo del bildungsroman, de la escritura autobiográfica o de la autoficción, sobresale, entre otros, el recurso de la metaficción en muchas de las obras citadas, por ejemplo, en La revuelta de los disfraces, Cenizas de Kalabó y Termes, Autorretrato con un infiel, Avión de ricos, ladrón de cerdos; el empleo de la intertextualidad en obras como La revuelta de los disfraces, Adjá-Adjá y otros relatos; el lenguaje popular y los localismos en Adjá-Adjá y otros relatos, Cenizas de Kalabó y Termes; los tonos propios de la parodia, la ironía, el sarcasmo o el humor en Cenizas de Kalabó y Termes, Autorretrato con un infiel, Nambula, Ecos de Malabo; el flashback en Autorretrato con un infiel, Avión de ricos, ladrón de cerdos; el carácter picaresco de los personajes en Adjá-Adjá y otros relatos. Además de todo ello, resalta la estrategia narrativa de la escritura con forma oral en Adjá-Adjá y otros relatos, en Arde el monte de noche, asociada en muchas ocasiones con la inserción de cuentos, como en Autorretrato con un infiel, y de historias y episodios interpolados, como en Avión de ricos, ladrón de cerdos. Entre otros muchos recursos destaca, a su vez, el cultivo del realismo mágico africano, del que un ejemplo muy significativo es Autorretrato con un infiel que, mediante el simbolismo de los nombres y a través de un marcado compromiso político-social, incide en una tierra africana mítica y fantástica recreada con elementos extraordinarios.

Un lugar significativo ocupa, en esta línea, El porteador de Marlow. Canción negra sin color, con una estética selecta que le ha llevado a ser relacionado con autores como Faulkner, Artaud, Kerouac, Soyinka, Carpentier, Bei Dao y Sony Labou Tansi, entre otros. El porteador de Marlow está conformado por narraciones breves en primera y tercera persona, mientras que Canción negra sin color presenta poemas y textos de prosa poética. En ambas secciones de la publicación emplea un lenguaje y un estilo brillantes, combinando diversos recursos retóricos con referencias cultas entre las que destacan las referidas a activictas por los derechos del pueblo africano, escritores, músicos y artistas. Refleja, con todos sus matices, la temática de la migración, pero con destacadas estrategias narrativas matizadas por un intenso diálogo con la tradición de la literatura universal, proyectando un discurso cosmopolita, híbrido e intertextual.

De tal modo, las letras guineoecuatorianas en lengua española, sin abandonar en ningún momento la articulación de estética y compromiso mediante una creación literaria que se convierte en un espejo de la realidad vivida en Guinea Ecuatorial, nos acercan cada vez con más intensidad a la manifestación de una nueva identidad del ecuatoguineano y de su literatura, una identidad propia que le otorga una voz destacada, híbrida y transnacional en el seno del actual mundo globalizado. 
Líneas éticas y estéticas en la narrativa guineoecuatoriana en lengua española

\section{Bibliografía}

AA.VV. (1977): Nueva narrativa guineana. Madrid: URGE.

Álvarez MÉndez, N. (2010): Palabras desencadenadas. Aproximación a la teoría literaria postcolonial y a la escritura hispano-negroafricana. Zaragoza, Prensas Universitarias de Zaragoza.

(2015): «El compromiso como ideario en la producción de Donato Ndongo-Bidyogo: resortes de un cántico erigido en conciencia moral de la sociedad», en I. DíAZ NARBONA (ed.), Literaturas hispanoafricanas: realidades y contextos. Madrid, Verbum, Biblioteca HIspanoafricana, pp. 1843.

Ávila Laurel, J. T. (2008): Avión de ricos, ladrón de cerdos. Barcelona, El Cobre. (2009): Arde el monte de noche. Madrid, Calambur Narrativa.

BALBOA BoneKE, J. (1985): El reencuentro. El retorno del exiliado. Madrid, Ediciones Guinea.

BHABHA, H. K. (1990): Nation and Narration. Londres / Nueva York, Routledge. (1994): The Location of Culture. Londres / Nueva York, Routledge.

DAVIES, J. M. (2007): Siete días en Bioko. Barcelona, Acidalia.

FANON, F. (1961): Les damnés de la terre. París, Maspero.

Mва Aвogo, C. A. (2007): El porteador de Marlow. Canción negra sin color. Madrid, Sial / Casa de África.

Mвomio Bacheng, J. (1996): El párroco de Niefang. Malabo, Ediciones del Centro Cultural HispanoGuineano.

- (1998): Huellas bajo tierra. Malabo, Ediciones del Centro Cultural Hispano-Guineano.

NdONGO-BIDYOGO, D. (1987): Las tinieblas de tu memoria negra. Madrid, Fundamentos.

(1997): Los poderes de la tempestad. Madrid, Morandi.

- (2000): «Literatura moderna hispanófona en Guinea Ecuatorial», en Afro-Hispanic Review, 19/1, pp. 39-44.

- (2007): El metro. Barcelona, El Cobre.

Ndongo-Bidyogo, D. y N'GOM, M’baré (2000): Literatura de Guinea Ecuatorial (Antología). Madrid, Sial Ediciones.

N'GOM FAYE, M'bare (1996): Diálogos con Guinea. Panorama de la literatura guineoecuatoriana de expresión castellana a través de sus protagonistas. Madrid, Labrys.

(comp.) 2004): La recuperación de la memoria: creación cultural e identidad nacional en la literatura hispano-negroafricana. Universidad de Alcalá, Servicios de Publicaciones.

Nkogo Esono, M. (2000): Adjá-Adjá y otros relatos. Ávila, Malamba.

- (2007): Nambula. Madrid, Morandi. (2009): Ecos de Malabo. Barcelona, El Cobre.

Nistal RosiQue, G. (2008): «Imagen de Guinea Ecuatorial en el siglo XXI a través de su literatura», en Oráfrica, revista de oralidad africana, 4, pp. 101-128.

NsUÉ ANGÜE, M. (1985): Ekomo. Madrid, UNED. 
OtABela Mewolo, J-D. y OnOMO ABena, S. (2004): Literatura emergente en español. Literatura de Guinea Ecuatorial. Madrid, Ediciones del Orto. (2008): Entre estética y compromiso. La obra de Donato Ndongo-Bidyogo. Madrid, UNED.

PEDrosA, J. M. (2009): «Isla, frontera, literatura» (Prólogo a Ávila Laurel, Juan Tomás. Arde el monte de noche). Madrid, Calambur Narrativa, pp. 7-9.

SAmpedro VizCAyA, B. y Fra-Molinero, B. (eds.) (2009): Equatorial Guinea, Afro-Hispanic Review, 28/2, otoño.

Siale Duangany, J. F. (2000): Cenizas de Kalabó y Termes. Ávila, Malamba.

- (2003): La revuelta de los disfraces. Ávila, Malamba.

- (2007): Autorretrato con un infiel. Barcelona, El Cobre.

URIBE, A. (2004): «El surgimiento de una literatura hispano-africana: Guinea Ecuatorial», en Boletín Hispánico Helvético, 4, pp. 93-103.

ZiElina Limonta, M. T. (2000): «Donato Ndongo-Bidyogo: un escritor guineano y su obra», en AfroHispanic Review, 19/1, pp. 106-116. 